\title{
Effects of Dapagliflozin on Volume Status When Added to Renin-Angiotensin System Inhibitors
}

\author{
Mie K. Eickhoff ${ }^{1, \dagger}$, Claire C. J. Dekkers ${ }^{2,+}{ }^{\oplus}$, Bart J. Kramers $^{3}$, Gozewijn Dirk Laverman ${ }^{4}$, \\ Marie Frimodt-Møller ${ }^{1}{ }^{(\mathbb{C}}$, Niklas Rye Jørgensen ${ }^{5}$, Jens Faber ${ }^{6,8}{ }^{(\mathbb{D}}$, A. H. Jan Danser ${ }^{7}$, \\ Ron T. Gansevoort ${ }^{3}$, Peter Rossing ${ }^{1,8}$, Frederik Persson ${ }^{1}$ and Hiddo J. L. Heerspink ${ }^{2, *(\mathbb{C})}$ \\ 1 Complications Research, Steno Diabetes Center Copenhagen, 2820 Gentofte, Denmark; \\ mie.klessen.eickhoff@regionh.dk (M.K.E.); marie.frimodt-moeller@regionh.dk (M.F.-M.); \\ peter.rossing@regionh.dk (P.R.); frederik.persson.01@regionh.dk (F.P.) \\ 2 Department of Clinical Pharmacy and Pharmacology, University Medical Center Groningen, \\ 9713 GZ Groningen, The Netherlands; c.c.j.dekkers@umcg.nl \\ 3 Department of Nephrology, University Medical Center Groningen, 9713 GZ Groningen, The Netherlands; \\ b.j.kramers@umcg.nl (B.J.K.); r.t.gansevoort@umcg.nl (R.T.G.) \\ 4 Department of internal medicine, Ziekenhuisgroep Twente, 7600 SZ Almelo, The Netherlands; \\ g.laverman@zgt.nl \\ 5 Department of Clinical Biochemistry, Rigshospitalet, 2100 Copenhagen Ø, Denmark; \\ niklas.rye.joergensen@regionh.dk \\ 6 Department of Endocrinology, Herlev \& Gentofte Hospital, 2730 Herlev, Denmark; Jens.Faber@regionh.dk \\ 7 Department of Internal Medicine, Erasmus Medical Center, 3015 CN Rotterdam, The Netherlands; \\ a.danser@erasmusmc.nl \\ 8 Faculty of Health and Medical Sciences, University of Copenhagen, 2200 Copenhagen N, Denmark \\ * Correspondence: h.j.lambers.heerspink@umcg.nl; Tel.: +31-50-361-7859; Fax: +31-50-361-4087 \\ + These authors contributed equally to this work.
}

Received: 29 April 2019; Accepted: 27 May 2019; Published: 31 May 2019

\begin{abstract}
Sodium glucose co-transporter 2 (SGLT2) inhibitors reduce the risk of heart and kidney failure in patients with type 2 diabetes, possibly due to diuretic effects. Previous non-placebo-controlled studies with SGLT2 inhibitors observed changes in volume markers in healthy individuals and in patients with type 2 diabetes with preserved kidney function. It is unclear whether patients with type 2 diabetes and signs of kidney damage show similar changes. Therefore, a post hoc analysis was performed on two randomized controlled trials $(n=69)$, assessing effects of dapagliflozin $10 \mathrm{mg} /$ day when added to renin-angiotensin system inhibition in patients with type 2 diabetes and urinary albumin-to-creatinine ratio $\geq 30 \mathrm{mg} / \mathrm{g}$. Blood and 24-h urine was collected at the start and the end of treatment periods lasting six and 12 weeks. Effects of dapagliflozin compared to placebo on various markers of volume status were determined. Fractional lithium excretion, a marker of proximal tubular sodium reabsorption, was assessed in 33 patients. Dapagliflozin increased urinary glucose excretion by $217.2 \mathrm{mmol} / 24 \mathrm{~h}$ ( $95 \%$ confidence interval (CI): from 155.7 to 278.7, $p<0.01$ ) and urinary osmolality by $60.4 \mathrm{mOsmol} / \mathrm{kg}$ (from 30.0 to $90.9, p<0.01$ ), compared to placebo. Fractional lithium excretion increased by $19.6 \%$ (from 6.7 to $34.2 ; p<0.01$ ), suggesting inhibition of sodium reabsorption in the proximal tubule. Renin and copeptin increased by $46.9 \%$ (from 21.6 to 77.4 , $p<0.01$ ) and $33.0 \%$ (from 23.9 to $42.7, p<0.01$ ), respectively. Free water clearance (FWC) decreased by $-885.3 \mathrm{~mL} / 24 \mathrm{~h}$ (from -1156.2 to $-614.3, p<0.01$ ). These changes in markers of volume status suggest that dapagliflozin exerts both osmotic and natriuretic diuretic effects in patients with type 2 diabetes and kidney damage, as reflected by increased urinary osmolality and fractional lithium excretion. As a result, compensating mechanisms are activated to retain sodium and water.
\end{abstract}

Keywords: SGLT2 inhibitor; dapagliflozin; diabetic nephropathy; heart failure 


\section{Introduction}

Sodium glucose co-transporter 2 (SGLT2) inhibitors reduce the incidence of heart failure and renal events in type 2 diabetes patients at risk for cardiovascular disease, as well as in patients with diabetes and chronic kidney disease [1-4]. The early separation of the event curves between the intervention and control group and the only modest reduction in hemoglobin $\mathrm{A}_{1 \mathrm{c}}\left(\mathrm{HbA}_{1 \mathrm{c}}\right)$ suggest that the long-term benefits conferred by SGLT2 inhibitors are unrelated to improvements in glycemic control $[1,2,4]$.

SGLT2 transporters are responsible for glucose and sodium reabsorption in the proximal tubule. Inhibition of SGLT2 promotes the urinary excretion of glucose and sodium, leading to osmotic diuresis and natriuresis. A few studies reported acute increases in urinary volume and sodium levels, supporting the natriuretic/diuretic properties of this drug class [5,6]. These effects dissipated during prolonged treatment, reflecting a transient natriuretic effect with a subsequent new steady state $[5,7]$. Other studies reported a decrease in plasma volume and interstitial fluid volume during SGLT2 inhibition, which would be in line with their natriuretic/diuretic profile $[8,9]$. These effects may, at least in part, explain the observed risk reduction of heart failure events in patients with diabetes [1-3].

Achieving and controlling optimal volume status can be a challenge in patients with diabetic kidney disease, due to the impaired net excretion of sodium. Guideline-recommended treatment for these patients consists of optimizing glucose and blood pressure control, the latter preferably with agents that intervene in the renin-angiotensin-aldosterone system. However, novel drugs that target $\mathrm{HbA}_{1 \mathrm{c}}$ and, at the same time, optimize volume control are a welcome addition to the therapeutic armamentarium for these patients.

Previous studies that assessed the effects of SGLT2 inhibitors on volume markers were performed in either healthy subjects or in patients with type 2 diabetes with preserved renal function, but not in patients with impaired renal function [5-7]. In addition, the previous studies did not control for placebo effects and included small populations, which limits the precision of the reported effect sizes and preclude subgroup analyses.

Therefore, we examined the effects of six to 12 weeks of treatment with SGLT2 inhibitor dapagliflozin compared to placebo on markers of volume status in type 2 diabetes patients with albuminuric kidney disease. In addition, we aimed to characterize the effects of dapagliflozin on specific markers of volume status in relevant subgroups.

\section{Experimental Section}

\subsection{Design and Participants}

This was a post hoc combined analysis of two similar studies: the IMPROVE study and the DapKid study. Both were prospective, double-blinded, placebo-controlled cross-over clinical trials designed to assess the albuminuria-lowering effects of dapagliflozin $10 \mathrm{mg} /$ day. The study designs and primary outcomes of both clinical trials were published previously $[10,11]$. In short, the IMPROVE study enrolled 34 patients with type 2 diabetes, an $\mathrm{HbA}_{1 \mathrm{c}}$ level between 55 and $100 \mathrm{mmoL} / \mathrm{moL}$, and a first morning void urinary albumin creatinine ratio (UACR) $\geq 100 \mathrm{mg} / \mathrm{g}$ and $<3500 \mathrm{mg} / \mathrm{g}$ from the Department of Internal Medicine Ziekenhuisgroep Twente, the Netherlands. Thirty-three patients completed the study and were included in the primary analysis. In the DapKid study, 36 patients completed the study. These were patients with type 2 diabetes, an $\mathrm{HbA}_{1 \mathrm{c}}$ level $>58 \mathrm{mmoL} / \mathrm{moL}$, and a first morning void UACR $\geq 30 \mathrm{mg} / \mathrm{g}$ from Steno Diabetes Center Copenhagen, Denmark. Both studies included patients between 18 and 75 years old with an estimated glomerular filtration rate (eGFR) $\geq 45 \mathrm{~mL} / \mathrm{min} / 1.73 \mathrm{~m}^{2}$. All patients were on a stable dose of renin-angiotensin-aldosterone system (RAAS) blocking treatment for at least four weeks prior to randomization.

Eligible patients were randomly assigned to two successive treatment periods in which they received dapagliflozin $10 \mathrm{mg} /$ day (AstraZeneca, Södertälje, Sweden) or matching placebo added to standard treatment (Figure S1, Supplementary Materials). The IMPROVE study consisted of six-week treatment periods with a wash-out period of six weeks in between. In the DapKid study, patients 
were assigned to two consecutive 12-week treatment periods without a wash-out period in between. For both studies, the study medication was provided by AstraZeneca, Södertälje, Sweden. The two studies were similar in design. The only difference between the studies was the duration of study periods (six vs. 12 weeks). We merged both studies under the assumption that a new steady state of body-fluid homeostasis arises early after start of SGLT2 inhibition (i.e., day two) [5,7].

Both studies were approved by the regional medical ethics committees (IMPROVE: METC 2014/111; DapKid: H-15006370). All patients gave written consent before any study-related procedures commenced. Both studies complied with the Declaration of Helsinki and Good Clinical Practice Guidelines. The IMPROVE study was registered with the Netherlands Trial Register (NTR 4439) and the DapKid study was registered with ClinicalTrials.gov (identifier NCT02914691).

\subsection{Measurements}

Office blood pressure was measured at the beginning and at the end of each treatment period. In both studies, the average of multiple blood pressure readings was recorded. Blood samples, three consecutive first-morning void urine samples, and 24-h urine samples were obtained at the start and end of the two treatment periods. In these blood samples, routine biochemistry assessments were performed, using the Roche COBAS 6000 analyzer series (Basel, Switzerland) in the IMPROVE study and the Ortho Clinical's VITROS 5600 (Raritan, Somerset, NJ, USA) in the DapKid study. Glomerular filtration rate was estimated (eGFR) using the Chronic Kidney Disease Epidemiology Collaboration (CKD-EPI) equation. In addition, urine and plasma samples were centrifuged, aliquoted, and stored at $-80^{\circ} \mathrm{C}$ for later assessment of the volume markers: copeptin, renin, $\mathrm{N}$-terminal pro b-type natriuretic peptide (NT-proBNP), and osmolality in the blood. Copeptin was measured as a surrogate marker of vasopressin. Unlike vasopressin, copeptin is easy to measure and is very stable ex vivo [12,13]. Glucose, sodium, and osmolality were also measured in the 24-h urine samples to calculate the fractional urinary sodium excretion, the urinary glucose excretion, and free water clearance. Free water clearance, the excreted solute-free water per unit time, was calculated as urine volume minus osmolar clearance. Osmolar clearance was calculated as ((urine osmolality $\times$ urine volume)/plasma osmolality) [8]. In the IMPROVE study, serum- and 24-h urine lithium were measured to calculate the fractional lithium excretion, which is a proxy for proximal tubular sodium reabsorption [14]. Lithium analyses were performed using inductively coupled plasma mass spectrometry (ICP-MS). Automated immunofluorescence assay on a KRYPTOR platform (Thermo Fisher, Waltham, MA, USA) was used to analyze copeptin in the DapKid study and KRYPTOR Compact analyzer (Brahms GMBH, Hennigsdorf, Germany) was used to analyze copeptin in the IMPROVE study. Renin concentration was measured using an immunoradiometric assay (Cisbio, Codolet, France) [15].

\subsection{Statistical Analysis}

Changes in individual outcomes during the intervention period and effects of the treatment were modeled by linear mixed-effects models with a patient-specific random intercept to account for the correlation of repeated measurements within patients. We included sequence, site, treatment, and site-by-treatment interaction as fixed variables in the model. Volume markers measured at the start of the first treatment period were characterized as baseline value. Due to differences in study design, we compared the end of the treatment periods and included the baseline value in the mixed model. Changes in all markers were analyzed in the merged database, as well as in both studies separately. Markers that were not normally distributed were log-transformed before entering the data into the mixed-effects model. The mean percentage changes of these log-transformed volume markers during dapagliflozin therapy versus placebo were derived by $\left(1-\exp \left[\right.\right.$ mean change] $x^{-} 100$ and the same was done for the $95 \%$ confidence limits. We tested for carry-over effect which was not present in either of the studies.

Secondly, the effects of dapagliflozin on specific volume markers, namely urinary osmolality, NT-proBNP, copeptin, and renin were assessed in the following baseline subgroups: $\mathrm{HbA}_{1 \mathrm{c}}$ level 
$<63 \mathrm{mmoL} / \mathrm{moL}$ vs. $\mathrm{HbA}_{1 \mathrm{c}} \geq 63 \mathrm{mmoL} / \mathrm{moL}$, eGFR $<82 \mathrm{~mL} / \mathrm{min} / 1.73 \mathrm{~m}^{2}$ vs. $\geq 82 \mathrm{~mL} / \mathrm{min} / 1.73 \mathrm{~m}^{2}$, UACR $<199.7 \mathrm{mg} / \mathrm{g}$ vs. $\geq 199.7 \mathrm{mg} / \mathrm{g}$, and use of diuretics at baseline (yes/no). The median was used to stratify the subgroups. Subgroup analyses were performed by adding relevant subgroups and an interaction term between treatment assignment and subgroup to the mixed models. Data processing and analyses were performed using SAS software, version 9.4 of the SAS System for Windows (SAS Institute Inc., Cary, NC, USA).

\section{Results}

\subsection{Baseline Characteristics}

Baseline characteristics of the IMPROVE study and the DapKid study were similar, except for renin, glucose, and $\mathrm{HbA}_{1 \mathrm{c}}$ levels, as well as urinary glucose excretion (Table S1, Supplementary Materials). The mean age of the subjects in the merged database was 62.7 years (8.8). Most of the subjects were male (82.6\%), and 44 subjects $(63.8 \%)$ used diuretics at baseline. The baseline variables related to glucose status, renal function, and volume status can be found in Table 1.

\subsection{Changes in $\mathrm{Hb} A_{1 c}$, Renal Function, and Markers of Volume Status}

Dapagliflozin, compared to placebo, decreased $\mathrm{HbA}_{1 \mathrm{c}}$ by $5.2 \mathrm{mmol} / \mathrm{mol}(95 \%$ confidence interval (CI): from 3.2 to $7.2 \mathrm{mmoL} / \mathrm{moL}, p<0.01$ ) (Table 1). Estimated GFR was decreased by $4.1 \mathrm{~mL} / \mathrm{min} / 1.73 \mathrm{~m}^{2}$ (from 2.4 to $5.9 \mathrm{~mL} / \mathrm{min} / 1.73 \mathrm{~m}^{2}, p<0.01$ ), and 24 -h urine albumin excretion was reduced by $52.0 \%$ (from 34.0 to $72.3 \%, p<0.01$ ), relative to placebo.

Dapagliflozin increased urinary glucose excretion by $217.2 \mathrm{mmol} / 24 \mathrm{~h}$ (from 155.7 to $278.7 \mathrm{mmoL} / 24 \mathrm{~h}$, $p<0.01$ ) and urinary osmolality by $60.4 \mathrm{mOsmoL} / \mathrm{kg}$ (from 30.0 to $90.9 \mathrm{mOsmoL} / \mathrm{kg}, p<0.01$ ), relative to placebo (Table 1 and Figure 1). Fractional sodium excretion was increased by $104.2 \%$ (from 19.0 to $189.4, p=0.02$ ), but there was no change in 24-h urinary sodium excretion (Table 1 and Figure 1). There was a $19.6 \%$ (from 6.7 to $34.2 \%, p<0.01$ ) increase in fractional lithium excretion relative to placebo, suggesting that, during chronic treatment with dapagliflozin, sodium reabsorption in the proximal tubule is inhibited (Table 1 and Figure 1). Compared to placebo, dapagliflozin reduced systolic blood pressure by $5.7 \mathrm{mmHg}$ (from 2.3 to $9.1 \mathrm{mmHg}, p<0.01$ ), decreased body weight by $1.3 \mathrm{~kg}$, and increased serum sodium and urea, but did not change NT-proBNP (Table 1). Furthermore, compared to placebo, renin increased by $46.9 \%$ (from 21.6 to $77.4 \%, p<0.01$ ) and copeptin increased by $33.1 \%$ (from 23.9 to $42.7 \%, p<0.01$; Table 1 and Figure 2). Free water clearance decreased by $-885.3 \mathrm{~mL} / 24 \mathrm{~h}$ (from -1156.2 to $-614.3 \mathrm{~mL} / 24 \mathrm{~h}, p<0.01$ ), relative to placebo (Table 1 and Figure 1). In general, the changes in volume markers were consistent between both studies (Table S2, Supplementary Materials).

As shown in Table 2, the effects of dapagliflozin on urinary osmolality, NT-proBNP, copeptin, and renin were consistent in subgroups defined by baseline $\mathrm{HbA}_{1 \mathrm{c}}$, eGFR, albuminuria, and diuretic use. 
Table 1. Volume markers at baseline, at the end of placebo treatment, and at the end of dapagliflozin treatment, and changes in volume markers during dapagliflozin treatment versus placebo in the merged database (IMPROVE study and DapKid study).

\begin{tabular}{|c|c|c|c|c|}
\hline Characteristics & At Baseline $(n=69)$ & End of Placebo Treatment & $\begin{array}{l}\text { End of Dapagliflozin } \\
\text { Treatment }\end{array}$ & $\begin{array}{l}\text { Change during Dapagliflozin vs. } \\
\text { Placebo (95\% CI; } p \text {-Value) }\end{array}$ \\
\hline Weight (kg) & $99.2(21.5)$ & $98.9(21.2)$ & $97.9(21.2)$ & $-1.3(-1.8,0.9 ; p<0.01)$ \\
\hline Body mass index $\left(\mathrm{kg} / \mathrm{m}^{2}\right)$ & $31.9(5.7)$ & $31.8(5.7)$ & $31.5(5.8)$ & $-0.39(-0.6,-0.2 ; p<0.01)$ \\
\hline Systolic blood pressure $(\mathrm{mmHg})$ & $141.2(15.2)$ & $140.4(14.5)$ & $134.7(15.9)$ & $-5.7(-9.1,-2.3 ; p<0.01)$ \\
\hline Diastolic blood pressure $(\mathrm{mmHg})$ & $79.8(8.6)$ & $78.1(9.4)$ & $76.8(8.3)$ & $-1.2(-2.9,0.5 ; p=0.2)$ \\
\hline Fasting plasma glucose $(\mathrm{mmoL} / \mathrm{L})$ & $9.8(3.6)$ & $10.0(3.4)$ & $8.2(2.8)$ & $-1.8(-2.6,-0.9 ; p<0.01)$ \\
\hline $\mathrm{HbA}_{1 \mathrm{c}}(\mathrm{mmoL} / \mathrm{moL})$ & $65.4(15.0)$ & 66.6 & 61.3 & $-5.2(-7.2,-3.2 ; p<0.01)$ \\
\hline Sodium $(\mathrm{mmoL} / \mathrm{L})$ & $139.2(2.7)$ & $139.6(2.8)$ & $140.5(2.8)$ & $0.9(0.4,1.5 ; p<0.01)$ \\
\hline Potassium (mmoL/L) & $4.3(0.5)$ & $4.3(0.4)$ & $4.2(0.4)$ & $-0.02(-0.1,0.1 ; p=0.61)$ \\
\hline Urea $(\mathrm{mmoL} / \mathrm{L})$ & $6.4(2.2)$ & $6.6(2.4)$ & $7.1(2.6)$ & $0.5(0.1,0.9 ; p=0.02)$ \\
\hline Osmolality $(\mathrm{mOsmoL} / \mathrm{kg})$ & $294.8(14.4)$ & $291.1(8.6)$ & $291.6(7.3)$ & $0.5(-1.5,2.6 ; p=0.61)$ \\
\hline Copeptin $(\mathrm{pmoL} / \mathrm{L}) \ddagger$ & $8.3(5.7,11.2)$ & $8.3(5.4,12.6)$ & $11.6(6.8,16.6)$ & $33.0 \%(23.9,42.7 ; p<0.01)$ \\
\hline $\operatorname{Renin}(\mathrm{ng} / \mathrm{L}) \ddagger$ & $37.1(17.1,85.0)$ & $33.6(16.0,70.1)$ & $59.3(21.1,101.0)$ & $46.9 \%(21.6,77.4 ; p<0.01)$ \\
\hline NT-proBNP (ng/L) ${ }^{\ddagger}$ & $103.0(35.0,205.5)$ & $107.5(43.8,227.0)$ & $105.0(48.0,185)$ & $-5.2 \%(-19.6,8.1 ; p=0.4)$ \\
\hline Estimated GFR (mL/min/1.73 m²) & $79.4(19.3)$ & $80.1(18.8)$ & $76.1(20.8)$ & $-4.1(-5.9,-2.4 ; p<0.01)$ \\
\hline $\mathrm{UACR}(\mathrm{mg} / \mathrm{g})^{\ddagger}$ & $199.7(102.3,405.3)$ & $202.3(106.3,480.0)$ & $133.7(75.3,282.3)$ & $-52.0 \%(-72.3,-34.0 ; p<0.01)$ \\
\hline Urinary volume $(\mathrm{mL} / 24 \mathrm{~h})$ & $2057(762)$ & $2120(741)$ & $2394(804)$ & $266.3(100.6,432.0 ; p<0.01)$ \\
\hline Urine glucose excretion $(\mathrm{mmoL} / 24 \mathrm{~h}) \ddagger$ & $21.5(2.0,130.2)$ & $23.0(2.0,154.0)$ & $211.3(121.1,512.5)$ & $217.2(155.7,278.7 ; p<0.01)$ \\
\hline Urinary osmolality (mOsmoL/kg) & $560.7(177.3)$ & $553.4(175.6)$ & $614.2(131.7)$ & $60.4(30.0,90.9 ; p<0.01)$ \\
\hline Urinary sodium excretion $(\mathrm{mmoL} / 24 \mathrm{~h})$ & $205.2(110.6)$ & $200.5(84.5)$ & $195.9(98.3)$ & $-4.5(-27.5,18.5 ; p=0.70)$ \\
\hline Fractional sodium excretion (\%) & $937.8(321.2)$ & $898.9(335.1)$ & $1006.3(384.8)$ & $104.2 \%(19.0,189.4 ; p=0.02)$ \\
\hline Fractional lithium excretion (\%) & $11,318.7(8984.9,17,344.4)$ & $10,484.6(8648.9,13,734.9)$ & $12,437.4(10,461.9,16,275.4)$ & $19.6 \%(6.7,34.2 ; p<0.01)$ \\
\hline Free water clearance $(\mathrm{FWC})(\mathrm{mL} / 24 \mathrm{~h})$ & $-1727.1(-1335.4)$ & $-1724.3(-1230.6)$ & $-2606.1(-1390.7)$ & $-885.3(-1156.2,-614.3 ; p<0.01)$ \\
\hline
\end{tabular}

Data are given as mean (SD) and $\ddagger$ median (25th-75th percentile). \# Fractional lithium excretion was only measured in the IMPROVE study and not in the DapKid study. 

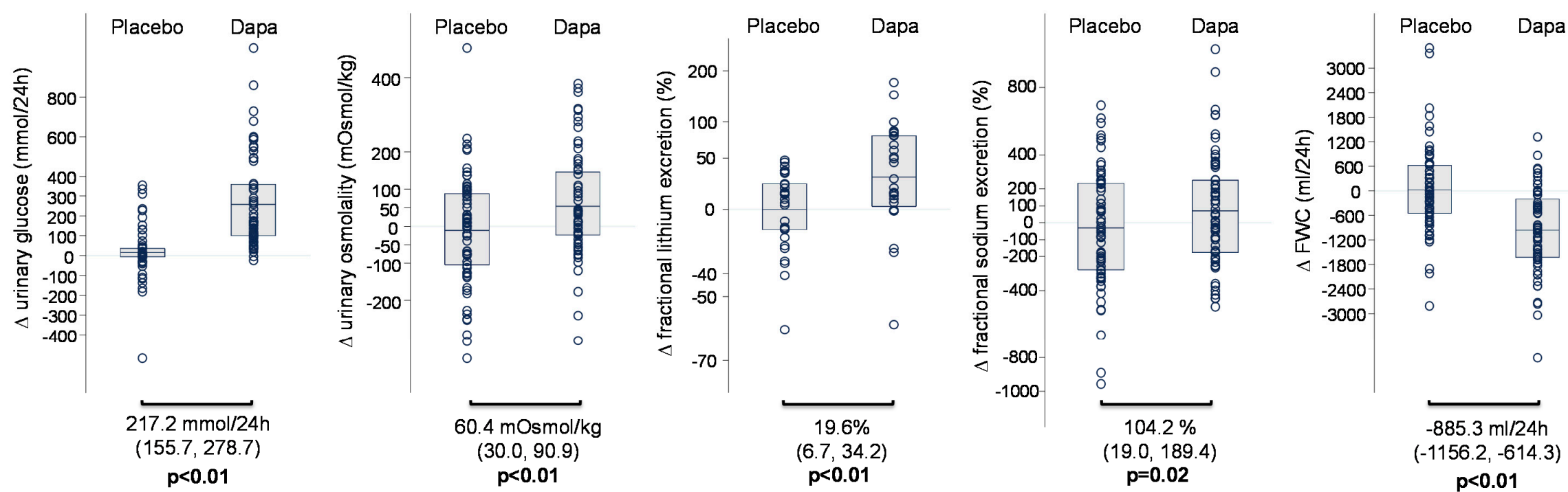

Figure 1. Volume markers at baseline, at the end of placebo treatment, at the end of dapagliflozin treatment, and changes in volume markers during dapagliflozin treatment versus placebo in the merged database (IMPROVE study and DapKid study). 

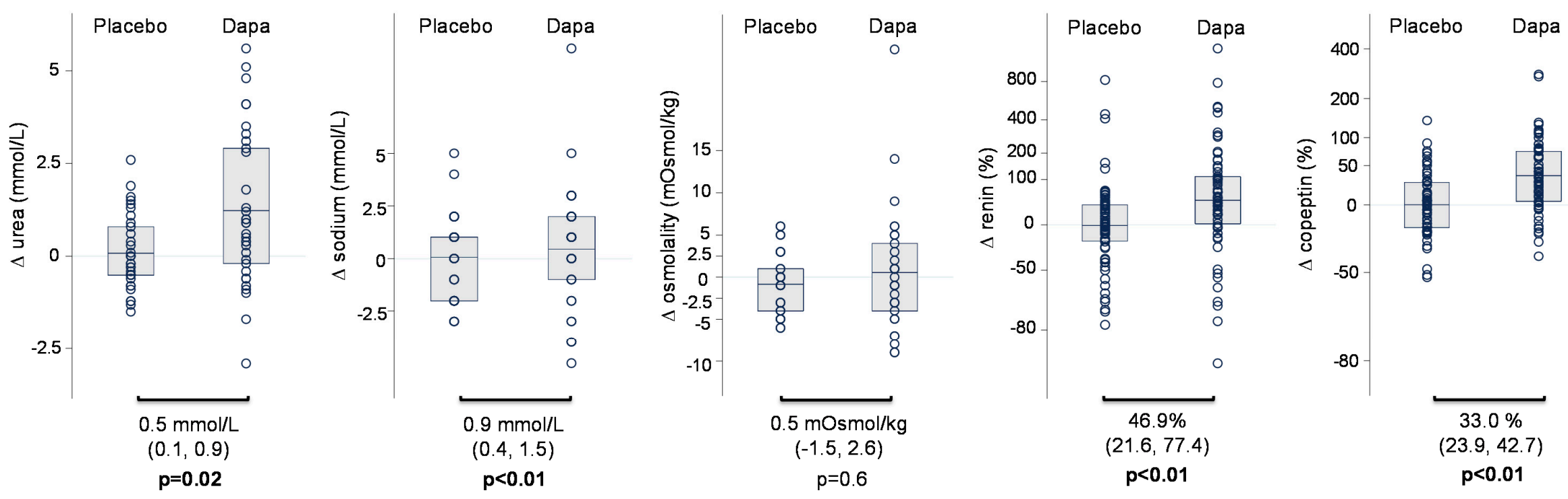

Figure 2. Changes in plasma volume markers during dapagliflozin treatment versus placebo treatment in the merged database. 
Table 2. Changes in urinary osmolality, NT-proBNP, and copeptin during dapagliflozin therapy versus placebo in various subgroups.

\begin{tabular}{|c|c|c|c|c|c|c|c|c|}
\hline $\begin{array}{l}\text { Baseline } \\
\text { Subgroups }\end{array}$ & $\begin{array}{c}\text { Mean Baseline } \\
\text { Urinary } \\
\text { Osmolality } \\
\text { (mOsmoL/kg) } \\
\text { (SD) }\end{array}$ & $\begin{array}{c}\text { Change in } \\
\text { Urinary } \\
\text { Osmolality } \\
\text { (mOsmoL/kg) } \\
\text { (95\% CI; } \\
p \text {-Value) }\end{array}$ & $\begin{array}{c}\text { Median } \\
\text { Baseline } \\
\text { NT-proBNP } \\
\text { (ng/L) } \\
\text { (IQR) }\end{array}$ & $\begin{array}{c}\text { Change in } \\
\text { NT-proBNP (\%) } \\
\text { (95\% CI; } \\
p \text {-Value) }\end{array}$ & $\begin{array}{c}\text { Median } \\
\text { Baseline } \\
\text { Copeptin } \\
\text { (pmoL/L) } \\
\text { (IQR) }\end{array}$ & $\begin{array}{c}\text { Change in } \\
\text { Copeptin (\%) } \\
(95 \% \mathrm{CI} ; \\
p \text {-Value) }\end{array}$ & $\begin{array}{c}\text { Median } \\
\text { Baseline Renin } \\
\text { (ng/L) } \\
\text { (IQR) }\end{array}$ & $\begin{array}{c}\text { Change in } \\
\text { Renin (\%) } \\
(95 \% \mathrm{CI} ; \\
p \text {-Value) }\end{array}$ \\
\hline Diuretics use & $554(168)$ & $63.1(24.7,101.5$; & $75\left(\begin{array}{ll}35 & 201)\end{array}\right.$ & $-3.8 \%(-22.2$ & $73(54112)$ & $29.6 \%(18.7,41.6$; & $38(19 \quad 85)$ & $52.6 \%(20.4,93.4 ;$ \\
\hline Yes $(\mathrm{N}=44)$ & $\begin{array}{l}554(168) \\
573(196)\end{array}$ & $\begin{array}{c}p<0.01) \\
591(82.110 .0\end{array}$ & $\begin{array}{r}75(35,201) \\
113(38,206)\end{array}$ & $\begin{array}{c}13.5 ; p=0.65) \\
7.1 \%(-33.6\end{array}$ & $\begin{array}{l}7.3(5.4,11.2) \\
90(59.10 .9)\end{array}$ & $\begin{array}{c}p<0.01) \\
391 \%(239561 .\end{array}$ & $\begin{array}{l}38(19,85) \\
29(17.72)\end{array}$ & $\begin{array}{c}p<0.01) \\
38.7 \%(1.6,89.3\end{array}$ \\
\hline No $(N=25)$ & & $p=0.02)$ & & $16.4 ; p=0.54)$ & & $p<0.01)$ & & $p=0.04)$ \\
\hline$p$ for interaction & & $p=0.19$ & & $p=0.39$ & & $p=0.41$ & & $p=0.08$ \\
\hline $\begin{array}{c}\mathrm{HbA}_{1 \mathrm{c}} \\
(\mathrm{mmoL} / \mathrm{moL})\end{array}$ & $532(175)$ & $\begin{array}{c}71.7(27.7,115.8 ; \\
p<0.01)\end{array}$ & $110(35,209)$ & $\begin{array}{c}4.1 \%(-16.2,25.8 ; \\
p=0.68)\end{array}$ & $7.5(5.6,11.2)$ & $\begin{array}{c}32.0 \%(19.0,46.5 ; \\
\quad p<0.01)\end{array}$ & $29(19,87)$ & $\begin{array}{c}32.2 \%(1.07,73.0 ; \\
p=0.04)\end{array}$ \\
\hline$<63$ & 589 (177) & $51.4(9.0,93.8$ & $100(35,201)$ & $-13.0 \%(-35.0$ & $9.0(5.8,14.0)$ & $35.3 \%(19.0,53.7$ & $40(15,85)$ & $62.7 \%(25.3$ \\
\hline$\geq 63$ & & $p=0.02)$ & & $5.8 ; p=0.18)$ & & $p<0.01)$ & & $111.2 ; p<0.01)$ \\
\hline $\mathrm{p}$ for interaction & & $p=0.51$ & & $p=0.76$ & & $p=0.49$ & & $p=0.56$ \\
\hline Estimated GFR & $509(152)$ & $65.4(21.2,109.5$ & $118\left(\begin{array}{ll}53 & 263)\end{array}\right.$ & $-4.8 \%(-26.1$ & $92(63164)$ & $36.7 \%(23.6,51.2 ;$ & $29(113)$ & $48.5 \%(13.3,94.7 ;$ \\
\hline$<82$ & $611(188)$ & $57.1(14.6,99.6$; & $66(35,150)$ & $-4.6 \%(-26.2$ & $7.1(4.5,10.0)$ & $29.5 \%(17.4,42.8$ & $41(11,70)$ & $46.0 \%(12.2,90.0$ \\
\hline$\geq 82$ & & $p<0.01)$ & & $15.3 ; p=0.63)$ & & $p<0.01)$ & & $p=0.01)$ \\
\hline $\mathrm{p}$ for interaction & & $p=0.68$ & & $p=0.85$ & & $p=b 0.46$ & & $p=0.66$ \\
\hline UACR (mg/g) & 591 (199) & $\begin{array}{c}76.8(33.6,120.0 ; \\
n<0.01)\end{array}$ & $75(35,201)$ & $\begin{array}{c}-10.3 \%-33.3 \\
5 \cdot p=030\end{array}$ & $77(58.109)$ & $\begin{array}{c}32.5 \% \\
n<0.91)\end{array}$ & $38(17,67)$ & $\begin{array}{c}45.4 \% \\
n<0.31\end{array}$ \\
\hline$<199.7$ & $532(151)$ & $46.6(3.7,89.5 ;$ & $112(53,263)$ & $-0.1 \%(-19.8$ & $8.9(5.7,11.2)$ & $33.5 \%(20.8,47.5$; & $37(19,85)$ & $49.0 \%(14.1,94.7$ \\
\hline$\geq 199.7$ & & $p=0.03)$ & & $20.0 ; p=0.99)$ & & $\begin{array}{c}p<0.01) \\
\text { p }\end{array}$ & & $\begin{array}{c}p<0.01) \\
\text { s. }\end{array}$ \\
\hline $\mathrm{p}$ for interaction & & $p=0.92$ & & $p=0.71$ & & $p=0.29$ & & $p=0.41$ \\
\hline
\end{tabular}




\section{Discussion}

The present study examined effects of dapagliflozin on volume markers in type 2 diabetes patients with micro- or macroalbuminuria. Dapagliflozin increased urinary osmolality and fractional lithium excretion, and it decreased blood pressure and weight after 6-12 weeks, compared to placebo. The observed increases in renin and copeptin suggest activation of compensatory mechanisms to retain sodium and water and restore volume homeostasis. Taken together, these data provide more insight into the natriuretic and diuretic effects of SGLT2 inhibition.

What does this study add to the existing literature? The present data confirm previous studies on the diuretic and natriuretic effects of SGLT2 inhibitors and extend these to a placebo-controlled setting. We also report for the first time the effect of chronic SGLT2 inhibition on fractional lithium excretion as a proxy for tubular sodium reabsorption inhibition, and we demonstrate activation of compensatory mechanisms to restore extracellular volume homeostasis during prolonged SGLT2 inhibition. Finally, prior studies included patients with type 2 diabetes and preserved kidney function, while our studies enrolled patients with type 2 diabetes and kidney damage in whom sodium and fluid homeostasis is often impaired.

Our results indicate that the diuretic effect of dapagliflozin can be attributed to both osmotic diuresis and natriuretic diuresis (Figure 3). The increase in urinary glucose excretion supports an osmotic diuretic effect, while increases in fractional lithium excretion suggest changes in sodium handling during dapagliflozin treatment. We note that the natriuretic effects of SGLT2 inhibitors appear to be weaker compared to traditional diuretics, as evidenced by smaller increases in renin and aldosterone in head-to-head studies $[6,7,9]$. The osmotic diuresis, thus, seems to be the driving component of the diuretic effects of SGLT2 inhibitors. We also note that the current observations were performed after 6-12 weeks of dapagliflozin treatment when patients established a new steady state in extracellular volume and when sodium intake matched sodium excretion. Hence, it is unlikely that the observed increase in fractional sodium excretion is a product of increased dietary sodium intake, since we did not observe changes in 24-h urinary sodium excretion. Fractional sodium excretion is calculated as the clearance of sodium divided by the creatinine clearance. The increase in fractional sodium excretion might, thus, be a consequence of decreased glomerular filtration.

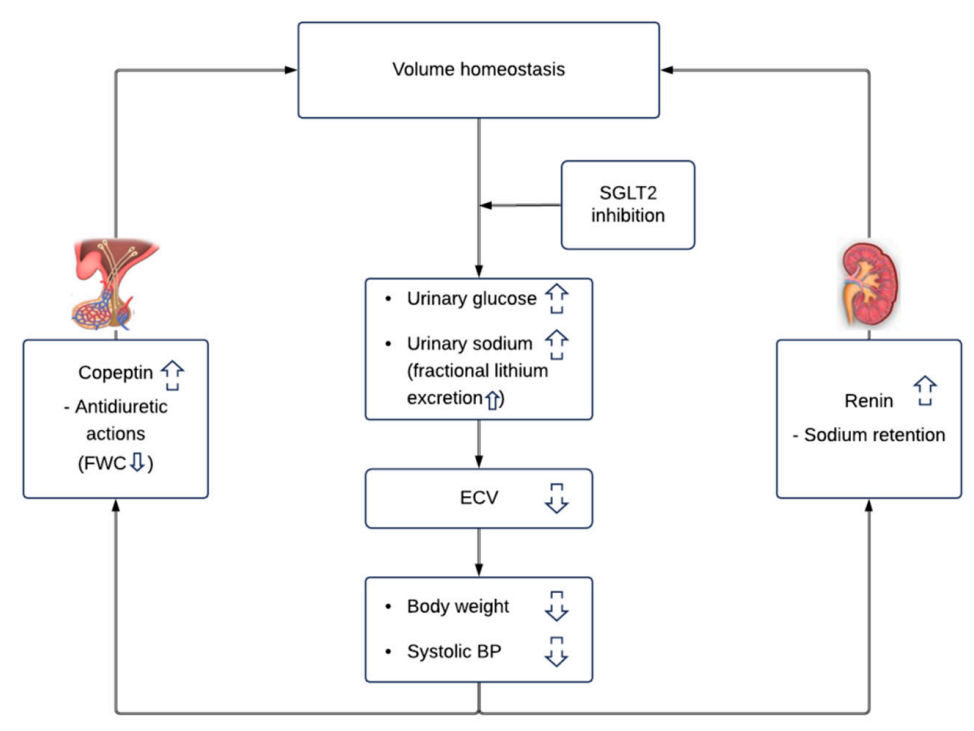

Figure 3. Effects of the sodium glucose co-transporter 2 (SGLT2) inhibitor dapagliflozin on volume homeostasis. Dapagliflozin increases urinary glucose and sodium excretion leading to increased urinary osmolality. Both natriuretic and osmotic diuresis will decrease extracellular volume and decrease body weight and systolic blood pressure. The reduction in extracellular volume activates compensatory mechanisms such as renin and copeptin to restore volume homeostasis. Abbreviations: ECV: extracellular volume, BP: blood pressure, FWC: free water clearance. 
Inhibition of sodium reabsorption in the proximal tubule and increased sodium delivery in the distal tubule will generally trigger compensatory mechanisms to maintain sodium and fluid homeostasis (Figure 3). Such effects were also observed in our study, even after 6-12 weeks of treatment with dapagliflozin. Firstly, increased sodium delivery in the distal tubule promotes renin secretion by the juxtaglomerular cells [16]. Increased secretion of copeptin, a surrogate marker of vasopressin, is another mechanism activated in the setting of increased diuresis and reduction in body-fluid volumes to promote water retention. The decrease in FWC may be a consequence of increased vasopressin secretion secondary to volume contraction and/or increased glucosuria. Finally, although not measured in our study, a reduction in plasma volume due to diuretic effects decreases medullary blood flow, which is expected to increase the abstraction of water in the descending limb of Henle (which is impermeable to sodium). This in turn leads to an increased sodium concentration, and an increased passive reabsorption of sodium further down the ascending loop of Henle to maintain fluid homeostasis [17].

The increases in osmotic and natriuretic diuresis, along with reductions in body weight and systolic blood pressure and the activation of compensatory mechanisms, as described above, indicate that dapagliflozin reduces plasma volume. Plasma volume contraction may also explain the modest, yet statistically significant increases in plasma sodium and urea. The finding that NT-proBNP did not change during dapagliflozin treatment was surprising, but was also observed in other dapagliflozin studies [9]. A possible explanation is that, in most studies, subjects were not evidently volume overloaded and had NT-proBNP levels in the normal range. Future studies in subjects with elevated NT-proBNP levels and volume overload are required to study this in more detail.

The effects of dapagliflozin on urinary osmolality, NT-proBNP, copeptin, and renin in the overall study population were consistent irrespective of $\mathrm{HbA}_{1 c}$, eGFR, albuminuria, or diuretic use at baseline. This finding adds to a growing body of evidence that the effects of SGLT2 inhibitors on volume states are consistent across a wide range of patients with type 2 diabetes, regardless of whether subjects used cardiovascular medication (such as diuretics), or whether they had renal impairment.

This study has limitations. Unfortunately, direct measurements of plasma volume were not available for the included studies. However, prior studies already showed that SGLT2 inhibitors decrease extracellular fluid/plasma volume $[8,9,18,19]$. We recognize that we combined two studies with different durations of treatment periods. The IMPROVE study consisted of six-week treatment periods, while the DapKid study had treatment periods of 12 weeks. Overall, there was generally a consistent trend in the changes of volume markers between both studies, as illustrated in Table S2 (Supplementary Materials). These data support the notion that differences in treatment periods did not influence the observed changes in volume markers, because a new steady sodium and water balance arises after a few days of treatment. There were also differences in baseline glycemic control between patients enrolled in the IMPROVE study (Almelo, Ziekenhuisgroep Twente) and patients enrolled in the DapKid study (Copenhagen, Steno Diabetes Center). We, therefore, adjusted all our analyses for recruitment location. Determining acute changes in volume markers was beyond the scope of these studies. The currently ongoing study "DAPASALT" (ClinicalTrials.gov identifier: NCT03152084) was designed to prospectively assess short-term and long-term changes in several volume-related markers, such as 24-h urinary sodium, blood pressure, and copeptin.

In conclusion, this study shows that dapagliflozin increased urinary osmolality, urinary glucose, and fractional lithium excretion, and it decreased blood pressure and body weight. These results suggest that dapagliflozin exerts a diuretic effect through both osmotic and natriuretic diuresis in individuals with type 2 diabetes and kidney damage. During prolonged treatment with dapagliflozin, compensatory mechanisms are activated to restore body-fluid homeostasis.

Supplementary Materials: The following are available online at http://www.mdpi.com/2077-0383/8/6/779/s1: Figure S1: Design of the IMPROVE study and the DapKid study; Table S1: Separate baseline characteristics in the IMPROVE study and DapKid study; Table S2: Separate changes in characteristics and volume markers during dapagliflozin treatment versus placebo in the IMPROVE study and DapKid study. 
Author Contributions: M.K.E. and C.C.J.D. were jointly and equally responsible for conceptualization, design, analysis and interpretation of data, drafting the article, and revising it, and provided intellectual content of critical importance to the work, along did a final approval of the version to be published. N.R.J., J.F., and A.H.J.D. were responsible for analysis of data, critically revised the article, provided intellectual content of critical importance to the work, and approved the final version to be published. B.J.K. and G.D.L. were responsible for interpretation of the data, critically revised the article, provided intellectual content of critical importance to the work, and approved the final version to be published. M.F.-M., R.T.G., P.R., F.P., and H.J.L.H. were responsible for conceptualization, design, and analysis and interpretation of data; they also critically revised the article, provided intellectual content of critical importance to the work, and approved the final version to be published.

Funding: Both studies were investigator initiated. The study medication was provided by AstraZeneca for both studies. Steno Diabetes Center Copenhagen received a grant from AstraZeneca to carry out the DapKid study. Additional tests were funded by the Novo Nordisk Foundation, grant no. NNF 14OC0013659.

Acknowledgments: We thank all the participants and research staff in both studies, the lab technician $\mathrm{B}$. Haandrikman at the University Medical Center Groningen, and the lab technicians Berit R. Jensen, Tina R. Juhl, Jessie A. Hermann and Anne G Lundgaard at Steno Diabetes Center Copenhagen.

Conflicts of Interest: C.C.J.D., B.J.K., M.F.-M., N.R.J., A.H.J.D., and R.T.G. report no conflicts of interest. M.K.E. has served as an educator for Astra Zeneca (all honoraria to institution). G.D.L. has received lecture fees from Sanofi, Astra Zeneca, and Jansen, and has served as a consultant for Abbvie, Sanofi, Novo Nordisk, Astra Zeneca, Boehringer Ingelheim, and MSD. J.F. has served as a consultant on advisory boards or as an educator for Novo Nordisk, Novartis, AstraZeneca, Eli Lilly, Otsuka, and Boehringer Ingelheim. P.R. has served as a consultant on advisory boards or as an educator for Astra Zeneca, Astellas, AbbVie, Novo Nordisk, Boehringer Ingelheim, Eli Lilly, Merck, Bayer (all honoraria to institution), has shares in Novo Nordisk, and has received research grants to institution from Novo Nordisk and Astra Zeneca. F.P. has served as a consultant on advisory boards or as an educator for Astra Zeneca, Novo Nordisk, Sanofi, Mundipharma, MSD, Boehringer Ingelheim, Novartis, and Amgen, and has received research grants to institution from Novo Nordisk, Amgen, and Astra Zeneca. H.J.L.H. is a consultant for and has received honoraria from AbbVie, Astellas, Astra Zeneca, Boehringer Ingelheim, Fresenius, Janssen, and Merck; he has a policy that all honoraria are paid to his employer. Astra Zeneca provided the study medication for both studies, but had no role in the design of the study; in the collection, analyses, or interpretation of data; in the writing of the manuscript, or in the decision to publish the results.

\section{References}

1. Zinman, B.; Wanner, C.; Lachin, J.M.; Fitchett, D.; Bluhmki, E.; Hantel, S.; Mattheus, M.; Devins, T.; Johansen, O.E.; Woerle, H.J.; et al. Empagliflozin, Cardiovascular Outcomes, and Mortality in Type 2 Diabetes. N. Engl. J. Med. 2015, 373, 2117-2128. [CrossRef] [PubMed]

2. Neal, B.; Perkovic, V.; Mahaffey, K.W.; De Zeeuw, D.; Fulcher, G.; Erondu, N.; Shaw, W.; Law, G.; Desai, M.; Matthews, D.R.; et al. Canagliflozin and Cardiovascular and Renal Events in Type 2 Diabetes. N. Engl. J. Med. 2017, 377, 644-657. [CrossRef] [PubMed]

3. Wiviott, S.D.; Raz, I.; Bonaca, M.P.; Bonaca, O.; Kato, E.T.; Cahn, A.; Silverman, M.S.; Zelniker, T.A.; Kuder, J.F.; Murphy, S.A.; et al. Dapagliflozin and Cardiovascular Outcomes in Type 2 Diabetes. N. Engl. J. Med. 2019, 380, 347-357. [CrossRef] [PubMed]

4. Perkovic, V.; Jardine, M.J.; Neal, B.; Bompoint, S.; Heerspink, J.L.; Charytan, D.M.; Edwards, R.; Agarwal, R.; Bakris, G.; Bull, S.; et al. Canagliflozin and Renal Outcomes in Type 2 Diabetes and Nephropathy. N. Engl. J. Med. 2019. [CrossRef] [PubMed]

5. Heise, T.; Jordan, J.; Wanner, C.; Heer, C.; Macha, S.; Biomath, M.M.D.; Lund, M.M.; Woerle, H.J.; Broedl, U.C. Pharmacodynamic Effects of Single and Multiple Doses of Empagliflozin in Patients with Type 2 Diabetes. Clin. Ther. 2016, 38, 2265-2276. [CrossRef] [PubMed]

6. Wilcox, C.S.; Shen, W.; Boulton, D.W.; Leslie, B.L.; Griffen, S.C. Interaction Between the Sodium-Glucose-Linked Transporter 2 Inhibitor Dapagliflozin and the Loop Diuretic Bumetanide in Normal Human Subjects. J. Am. Heart Assoc. 2018, 7. [CrossRef] [PubMed]

7. Solini, A.; Giannini, L.; Seghieri, M.; Seghieri, E.; Taddei, S.; Ghiadoni, L.; Bruno, R.M. Dapagliflozin acutely improves endothelial dysfunction, reduces aortic stiffness and renal resistive index in type 2 diabetic patients: A pilot study. Cardiovasc. Diabetol. 2017, 16, 138. [CrossRef] [PubMed]

8. Hallow, K.M.; Helmlinger, G.; Greasley, P.J.; McMurray, J.J.V.; Boulton, D.W. Why do SGLT2 inhibitors reduce heart failure hospitalization? A differential volume regulation hypothesis. Diabetes Obes. Metab. 2018, 20, 479-487. [CrossRef] [PubMed] 
9. Lambers Heerspink, H.J.; de Zeeuw, D.; Wie, L.; Leslie, B.; List, J. Dapagliflozin a glucose-regulating drug with diuretic properties in subjects with type 2 diabetes. Diabetes Obes. Metab. 2013, 15, 853-862. [CrossRef] [PubMed]

10. Petrykiv, S.I.; Laverman, G.D.; de Zeeuw, D.; Heerspink, H.J.L. The albuminuria-lowering response to dapagliflozin is variable and reproducible among individual patients. Diabetes Obes. Metab. 2017, 19, 1363-1370. [CrossRef] [PubMed]

11. Eickhoff, M.K.; Olsen, F.J.; Frimodt-Møller, M.; Diaz, L.J.; Faber, J.; Jensen, M.T.; Rossing, P.; Persson, F. Effect of Dapagliflozin on Cardiac Function in Patients with Type 2 Diabetes and Albuminuria. Presented at EASD, Berlin, Germany, 1-5 October 2018.

12. Heida, J.E.; Boesten, L.S.M.; Ettema, E.M.; Kobold, A.C.M.; Franssen, C.F.M.; Gansevoort, R.T.; Zittema, D. Comparison of ex vivo stability of copeptin and vasopressin. Clin. Chem. Lab. Med. 2017, 55, 984-992. [CrossRef] [PubMed]

13. Morgenthaler, N.G.; Struck, J.; Alonso, C.; Bergmann, A. Assay for the measurement of copeptin, a stable peptide derived from the precursor of vasopressin. Clin. Chem. 2006, 52, 112-119. [CrossRef] [PubMed]

14. Koomans, H.A.; Boer, W.H.; Dorhout Mees, E.J. Evaluation of lithium clearance as a marker of proximal tubule sodium handling. Kidney Int. 1989, 36, 2-12. [CrossRef] [PubMed]

15. Fisher, N.D.; Jan Danser, A.H.; Nussberger, J.; Dole, W.P.; Hollenberg, N.K. Renal and hormonal responses to direct renin inhibition with aliskiren in healthy humans. Circulation 2008, 117, 3199-3205. [CrossRef] [PubMed]

16. Martini, A.G.; Danser, A.H.J. Juxtaglomerular Cell Phenotypic Plasticity. High Blood Press. Cardiovasc. Prev. 2017, 24, 231-242. [CrossRef] [PubMed]

17. Roman, R.J.; Zou, A.P. Influence of the renal medullary circulation on the control of sodium excretion. Am. J. Physiol. 1993, 265, R963-R973. [CrossRef] [PubMed]

18. Sha, S.; Polidori, D.; Heise, T.; Natarajan, J.; Farrell, K.; Wang, S.S.; Sica, D.; Rothenberg, P.; Plum-Mörschel, L. Effect of the sodium glucose co-transporter 2 inhibitor canagliflozin on plasma volume in patients with type 2 diabetes mellitus. Diabetes Obes. Metab. 2014, 16, 1087-1095. [CrossRef] [PubMed]

19. Ohara, K.; Masuda, T.; Murakami, T.; Imai, T.; Yoshizawa, H.; Nakagawa, S.; Okada, M.; Miki, A.; Myoga, A.; Sugase, T.; et al. Effects of the sodium-glucose cotransporter 2 inhibitor dapagliflozin on fluid distribution: A comparison study with furosemide and tolvaptan. Nephrology 2018. [CrossRef] [PubMed]

(C) 2019 by the authors. Licensee MDPI, Basel, Switzerland. This article is an open access article distributed under the terms and conditions of the Creative Commons Attribution (CC BY) license (http://creativecommons.org/licenses/by/4.0/). 